\title{
Surgical treatments for men with benign prostatic enlargement: cost effectiveness study
}

\author{
Nigel Armstrong, health economist, ${ }^{1}$ Luke Vale, professor of health technology assessment, ${ }^{2}$ Mark Deverill, \\ senior research fellow, ${ }^{1}$ Ghulam Nabi, clinical lecturer, ${ }^{3}$ Samuel McClinton, consultant urologist, ${ }^{3}$ James \\ N'Dow, professor of urology, ${ }^{3}$ Robert Pickard, senior clinical lecturer, ${ }^{4}$ for the BPE Study Groupfor the BPE \\ Study Group
}

\section{${ }^{1}$ Institute of Health and Society, Newcastle University, Newcastle upon Tyne NE2 4AA \\ ${ }^{2}$ Health Services Research Unit and Health Economics Research Unit, Institute of Applied Health \\ Sciences, University of Aberdeen, Aberdeen AB25 2ZD \\ ${ }^{3}$ Academic Urology Unit, Institute of Applied Health Sciences, \\ University of Aberdeen \\ ${ }^{4}$ Urology Research Group, Institute of Cellular Medicine, Newcastle University, Newcastle upon Tyne NE2 4HH \\ Correspondence to: R Pickard} r.s.pickard@ncl.ac.uk

Cite this as: BMJ 2009;338:b1288 doi:10.1136/bmi.b1288

\section{ABSTRACT}

Objective To determine which surgical treatment for lower urinary tract symptoms suggestive of benign prostate enlargement is cost effective.

Design Care pathways describing credible treatment strategies were decided by consensus. Cost-utility analysis used Markov modelling and Monte Carlo simulation.

Data sources Clinical effectiveness data came from a systematic review and an individual level dataset. Utility values came from previous economic evaluations. Costs were calculated from National Health Service (NHS) and commercial sources.

Methods The Markov model included parameters with associated measures of uncertainty describing health states between which individuals might move at three monthly intervals over 10 years. Successive annual cohorts of 25000 men were entered into the model and the probability that treatment strategies were cost effective was assessed with Monte Carlo simulation with 10000 iterations.

Results A treatment strategy of initial diathermy vaporisation of the prostate followed by endoscopic holmium laser enucleation of the prostate in case of failure to benefit or subsequent relapse had an $85 \%$ probability of being cost effective at a willingness to pay value of $£ 20000$ ( $€ 21595, \$ 28686$ )/quality adjusted life year (QALY) gained. Other strategies with diathermy vaporisation as the initial treatment were generally cheaper and more effective than the current standard of transurethral resection repeated once if necessary. The use of potassium titanyl phosphate laser vaporisation incurred higher costs and was less effective than transurethral resection, and strategies involving initial minimally invasive treatment with microwave thermotherapy were not cost effective. Findings were unchanged by wide ranging sensitivity analyses.

Conclusion The outcome of this economic model should be interpreted cautiously because of the limitations of the data used. The finding that initial vaporisation followed by holmium laser enucleation for failure or relapse might be advantageous both to men with lower urinary tract symptoms and to healthcare providers requires confirmation in a good quality prospective clinical trial before any change in current practice. Potassium titanyl phosphate laser vaporisation was unlikely to be cost effective in our model, which argues against its unrestricted use until further evidence of effectiveness and cost reduction is obtained.

\section{INTRODUCTION}

Evaluation of treatments for chronic health conditions requires studies of both effectiveness and cost effectiveness over the long term to identify how best to use the available budget. Benign prostatic enlargement caused by hyperplasia of the gland is an inevitable and progressive accompaniment to ageing in men. It is the main cause of lower urinary tract symptoms, such as frequency and poor flow, with a prevalence of about $30 \%$ in men aged over 60 , amounting to 1.8 million in the United Kingdom. ${ }^{1}$ Treatments for urinary symptoms presumed to be caused by benign prostatic enlargement control symptoms rather than lead to a cure, giving a long term risk of disease progression despite an initial response. ${ }^{2}$ Endoscopic removal of prostate tissue, typically by transurethral resection (TURP), is usually recommended to men who have not benefited from behavioural or drug treatment as it offers a high (70-80\%) chance of benefit and a low ( $1 \%$ per year) risk of retreatment. About 25000 such procedures are carried out annually in England at a cost of $£ 53 \mathrm{~m}(€ 57 \mathrm{~m}$, $\$ 76 \mathrm{~m})$. Despite sustained effectiveness, transurethral resection carries the risk of major haemorrhage and myocardial stress. ${ }^{3}$ Consequently, alternative surgical options have been trialled to reduce treatment morbidity but maintain effectiveness.

In a systematic review of effectiveness we concluded that newer technologies, such as microwave thermotherapy and diathermy or laser vaporisation, do improve symptoms and reduce risk but have higher rates of retreatment than transurethral resection. ${ }^{45}$ According to personal preference, men seeking treatment might trade off this reduced effectiveness for the reduced risk. For most this would result in successful treatment but a minority would have the inconvenience and exposure to risk of having to have a second 
more effective but potentially more morbid procedure. This might also give improvement from a healthcare perspective as use of the more morbid and costly treatments would be reduced. Such treatment sequences reflect current practice, particularly in the United States, where office based minimally invasive treatments are more widely used. Previous studies of health economics focused on single treatments without allowance for repeat or alternative treatment and provided only limited cost breakdown and sensitivity analysis, restricting generalisability across healthcare systems..$^{6-8}$ We modelled the use of plausible strategies of sequential treatments to maintain symptom control over an appropriate time span to determine which is most likely to be cost effective.

\section{METHODS}

\section{Model design}

We constructed a Markov model to investigate cost utility of each considered treatment option with effects measured by quality adjusted life years (QALYs) and costs $(£)$ at 2006 prices discounted at $3.5 \%$. ${ }^{9}$ The perspective was the UK's NHS, with treatments taking place in appropriately equipped hospitals served by specialist urologists already competent to carry out the procedures.

\section{Treatment options and care pathways}

The standard procedure was transurethral resection, with failure to benefit or subsequent relapse managed by a second transurethral resection carried out only if urodynamics confirmed obstruction of the bladder outlet. Alternative treatments were categorised into three groups: minimally invasive, characterised by no tissue removal and ambulatory care; tissue ablative, signifying the use of differing energy sources to partially remove prostate tissue; and near total removal of prostate by holmium laser enucleation (HoLEP). Appraisal of the evidence base for effectiveness, ${ }^{45}$ current practice, and commercial availability identified transurethral microwave thermotherapy (TUMT) and diathermy vaporisation (TUVP) as typifying the minimally invasive and tissue ablative groups, respectively. We also included potassium titanyl phosphate (KTP) laser vaporisation in the model as a substitute for diathermy vaporisation given its current clinical

Table 1|Schematic illustrating 23 treatment strategies tested in model. Each treatment strategy involved sequence of between one and five individual treatments. For each sequence " 1 " represents first treatment with " 2 ," " 3 ," " 4 ," and " 5 " indicating subsequent treatments administered after treatment failure or relapse of symptoms after initial success

\begin{tabular}{|c|c|c|c|c|c|c|}
\hline & \multicolumn{2}{|c|}{ Microwave thermotherapy } & \multirow[b]{2}{*}{ Diathermy vaporisation* } & \multicolumn{2}{|c|}{ Transurethral resection } & \multirow{2}{*}{$\begin{array}{l}\text { Holmium lase } \\
\text { enucleation }\end{array}$} \\
\hline & $1 \mathrm{st}$ & 2nd & & $1 \mathrm{st}$ & 2nd & \\
\hline \multicolumn{7}{|c|}{ One treatment } \\
\hline Strategy 1 & 1 & - & - & - & - & - \\
\hline Strategy 2 & - & - & 1 & - & - & - \\
\hline Strategy 3 & - & - & - & 1 & - & - \\
\hline Strategy 4 & - & - & - & - & - & 1 \\
\hline \multicolumn{7}{|c|}{ Two treatments } \\
\hline Strategy 5 & 1 & 2 & - & - & - & - \\
\hline Strategy 6 & 1 & - & 2 & - & - & - \\
\hline Strategy 7 & 1 & - & - & 2 & - & - \\
\hline Strategy 8 & 1 & - & - & - & - & 2 \\
\hline Strategy 9 & - & - & 1 & 2 & - & - \\
\hline Strategy 10 & - & - & 1 & - & - & 2 \\
\hline Strategy 11 & - & - & - & 1 & 2 & - \\
\hline \multicolumn{7}{|c|}{ Three treatments } \\
\hline Strategy 12 & 1 & 2 & 3 & - & - & - \\
\hline Strategy 13 & 1 & 2 & - & 3 & - & - \\
\hline Strategy 14 & 1 & 2 & - & - & - & 3 \\
\hline Strategy 15 & 1 & - & 2 & 3 & - & - \\
\hline Strategy 16 & 1 & - & 2 & - & - & 3 \\
\hline Strategy 17 & 1 & - & - & 2 & 3 & - \\
\hline Strategy 18 & - & - & 1 & 2 & 3 & - \\
\hline \multicolumn{7}{|c|}{ Four treatments } \\
\hline Strategy 19 & 1 & 2 & 3 & 4 & - & - \\
\hline Strategy 20 & 1 & 2 & 3 & - & - & 4 \\
\hline Strategy 21 & 1 & - & 2 & 3 & 4 & - \\
\hline Strategy 22 & 1 & 2 & - & 3 & 4 & - \\
\hline \multicolumn{7}{|c|}{ Five treatments } \\
\hline Strategy 23 & 1 & 2 & 3 & 4 & 5 & - \\
\hline
\end{tabular}


popularity. ${ }^{10}$ A clinical expert group, consisting of four urologists from two centres, identified by consensus clinically appropriate sequences of escalating surgical intervention according to treatment mechanism and effect on remaining prostate tissue. Sequences were defined by a set of rules reflecting current and likely future use of each method: treatments always proceeded from less to more invasive; minimally invasive treatments could be repeated only once; tissue ablative and holmium laser enucleation procedures could not be repeated because of the effect on remaining prostate tissue and near total removal, respectively; and transurethral resection could be repeated only once and only after confirmation of obstruction of the bladder outlet (table 1). ${ }^{11}$

\section{Population of patients}

The population was men with symptoms (international prostate symptom score (IPSS) $>7$ ) with presumed benign prostatic enlargement without specification of prostate size and no existing relevant complications, who required transurethral resection. The mean age was set at 70, the mid-point of the age range for men undergoing this surgery.

\section{Model structure}

We constructed a Markov model describing the sequence of events and main health states that men might find themselves in after the defined treatment strategies. The cycle length was set at three months, the period over which benefit would occur and short term adverse events resolve. We chose a time horizon of 10 years as this was the period over which the population would be likely to seek active treatment and current technologies would remain relevant. The model was run by entering 10 successive annual cohorts of 25000 men, the number receiving treatment each year in the NHS in England. We chose a multiple cohort design to better model the effects of applying sequences of escalating treatment and where progressively fewer members of a cohort would need additional surgery. The design also simulates the purchase of new equipment as required over the stated time horizon.

\section{Definition of health states}

We defined six health states: treatment, remission, no remission, remission with incontinence, no remission with incontinence, and death. Remission was defined as a more than $10 \%$ improvement in the international prostate symptom score, equivalent, for the population under study, to the 3 point reduction noticeable by men undergoing treatment for symptoms presumed to be caused by benign prostatic enlargement. ${ }^{12}$ The number of cycles spent by each individual in this state was determined by the probability of relapse

\begin{tabular}{|c|c|c|c|c|}
\hline Condition & Value* & Standard error $(95 \% \mathrm{Cl})$ & Source & Assigned distribution \\
\hline \multicolumn{5}{|l|}{ Utility values } \\
\hline \multicolumn{5}{|l|}{ Health states: } \\
\hline Remission & 1.00 & 0 & Kok et al ${ }^{15}$ & Beta \\
\hline No remission & 0.94 & $0.009(0.92$ to 0.96$)$ & Kok et $\mathrm{al}^{15}$ & Beta \\
\hline Incontinence & 0.89 & $0.006(0.88$ to 0.91$)$ & Ackerman et $\mathrm{al}^{16}$ & Beta \\
\hline \multicolumn{5}{|l|}{ Adverse effects†: } \\
\hline Urinary retention & 0.89 & 0.012 (0.87 to 0.92$)$ & Ackerman et al ${ }^{16}$ & Beta \\
\hline Bladder neck stenosis & 0.95 & $0.001(0.95$ to 0.96$)$ & Ackerman et al ${ }^{16}$ & Beta \\
\hline Urinary tract infection & 0.93 & $0.004(0.92$ to 0.94$)$ & Ackerman et al ${ }^{16}$ & Beta \\
\hline Transurethral resection syndrome & 0.81 & $0.022(0.77$ to 0.85$)$ & Ackerman et al ${ }^{16}$ & Beta \\
\hline \multicolumn{5}{|l|}{ Miscellaneous variables } \\
\hline \multicolumn{5}{|l|}{ Risks: } \\
\hline $\begin{array}{l}\text { Transurethral resection after urinary } \\
\text { retention }\end{array}$ & 0.5 & 0.05 (0.40 to 0.6$)$ & Expert opinion & Beta \\
\hline Urge type incontinence & 0.95 & 0.02 (0.91 to 0.99 ) & Expert opinion & Beta \\
\hline \multicolumn{5}{|l|}{ Costs: } \\
\hline $\begin{array}{l}\text { Baseline treatment (including mean length } \\
\text { of stay) (£) }\end{array}$ & 1862 & (1546 to 2195$) \ddagger$ & NHS $2006^{17}$ & Lognormal \\
\hline Urology ward bed day $(£)$ & 250 & (141 to 443$) \ddagger$ & NHS $2006^{17}$ & Lognormal \\
\hline $\begin{array}{l}\text { Length of stay after transurethral resection } \\
\text { syndrome (days) }\end{array}$ & 2 & 0.51 (1 to 3$)$ & Expert opinion & Normal \\
\hline Length of stay after urinary infection (days) & 3 & $1.4(0.25$ to 5.75$)$ & Expert opinion & Normal \\
\hline Urodynamic test (£) & 125 & 16 (92 to 157$)$ & NHS $2005^{17}$ & Normal \\
\hline Transfusion (£) & 1270 & 323 (635 to 1905$)$ & NHS tariff & Normal \\
\hline Oxybutynin (£) & 166 & (65 to 267 )§ & NHS drug tariff & Uniform \\
\hline
\end{tabular}

*Risk unless otherwise stated.

†Age adjusted mortality rates estimated from UK life tables and applied equally throughout time horizon without weighting according to procedure.

¥Where log distributions have been used, standard error is omitted to avoid inconsistency with confidence interval, which is expressed as actual relative risk.

§Limits of uniform distribution. 
after an initially successful treatment derived from long term observation data. The state of "no remission" was entered with the probability of initial failure or subsequent relapse for that particular treatment. Incontinence, defined as leakage of urine of sufficient degree to make an individual seek help and therefore result in additional treatment, was the only complication we included in the model. If this occurred no further treatment was possible and only transitions from remission to no remission or to death could occur. All other complications (urinary retention, bladder neck stenosis and/or urethral stricture, blood transfusion (a measure of severe bleeding), transurethral syndrome, and urinary infection) were considered as short term and were assumed to have been resolved within the three month treatment state. Retrograde ejaculation was not included as it is generally of little trouble to the population of men under study, ${ }^{13}$ and erectile dysfunction was not included as incidence was similar for all interventions and for untreated men. ${ }^{4514}$ Death was modelled as an absorbing state with age dependent transition probabilities calculated from UK life tables without weighting according to procedure. If the state of no remission-no incontinence was entered and further treatments were possible in the defined sequence then transition to the next treatment was allowed. If the individual was in the no remission state at the end of the treatment sequence then the only transition possible was to death.

\section{Data sources}

Utility values

We derived utility values for each health state from previous studies that used time trade-off ${ }^{15}$ and standard gamble $^{16}$ techniques, adjusted for total symptom score and for the presence of incontinence (table 2).

\section{Probabilities}

Remission -We calculated the probability of individual men entering the remission state after treatment as 1 - probability of relapse. We determined this probability from an individual level dataset containing

Table 3|Parameter values for transurethral resection and holmium laser enucleation used to specify Monte Carlo simulation in decision analytical model

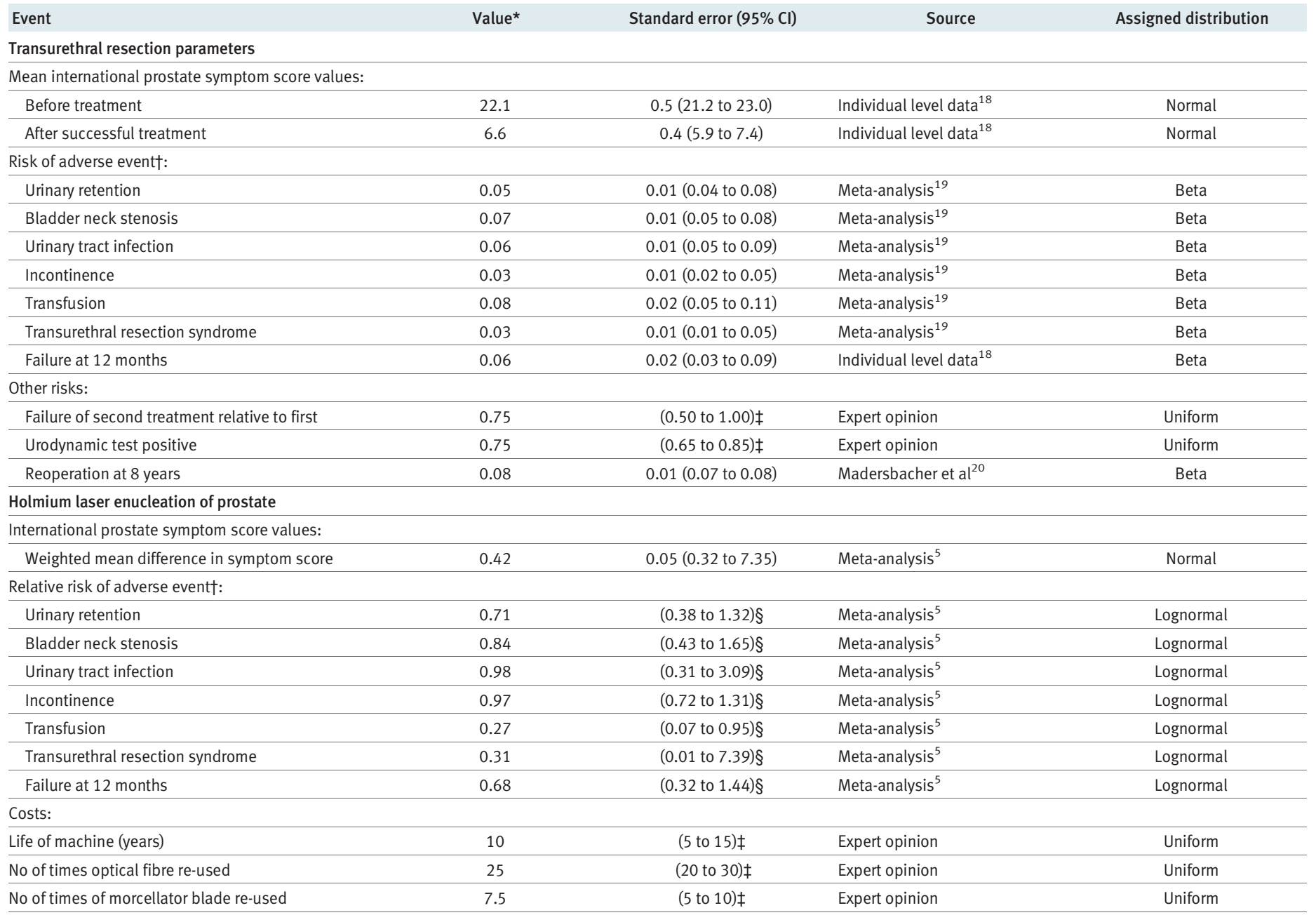

No of times of morcellator blade re-used

†Age adjusted mortality rates were estimated from United Kingdom life tables and applied equally throughout the time horizon without weighting according to procedure. flimits of the uniform distribution.

§Where log distributions have been used, standard error is omitted to avoid inconsistency with confidence interval, which is expressed as actual relative risk 
Table $4 \mid$ Parameter values for diathermy vaporisation, potassium titanyl phosphate laser vaporisation, and microwave thermotherapy used to specify Monte Carlo simulation in decision analytical model

\begin{tabular}{|c|c|c|c|c|}
\hline Event & Value* $^{*}$ & Standard error $(95 \% \mathrm{Cl})$ & Source & Assigned distribution \\
\hline \multicolumn{5}{|l|}{ Diathermy vaporisation } \\
\hline Weighted mean difference in IPSS & -0.18 & $0.23(-0.63$ to 0.26$)$ & Meta-analysis ${ }^{5}$ & Normal \\
\hline \multicolumn{5}{|l|}{ Relative risk of adverse event†: } \\
\hline Urinary retention & 2.12 & (1.23 to 3.68$) \ddagger$ & Meta-analysis ${ }^{5}$ & Lognormal \\
\hline Bladder neck stenosis & 0.91 & $(0.45$ to 1.85$) \ddagger$ & Meta-analysis ${ }^{5}$ & Lognormal \\
\hline Urinary tract infection & 0.65 & (0.40 to 1.08$) \ddagger$ & Meta-analysis $^{5}$ & Lognormal \\
\hline Incontinence & 0.92 & (0.69 to 1.21$) \ddagger$ & Meta-analysis ${ }^{5}$ & Lognormal \\
\hline Transfusion & 0.19 & $(0.08$ to 0.44$) \ddagger$ & Meta-analysis ${ }^{5}$ & Lognormal \\
\hline Transurethral resection syndrome & 0.59 & $(0.17$ to 2.12$) \ddagger$ & Meta-analysis $^{5}$ & Lognormal \\
\hline Failure at 12 months & 1.04 & (0.53 to 2.07$) \ddagger$ & Meta-analysis ${ }^{5}$ & Lognormal \\
\hline \multicolumn{5}{|c|}{ Potassium titanyl phosphate vaporisation $\ddagger$} \\
\hline Weighted mean difference in IPSS & -1.3 & $0.6(-2.5$ to $(-0.1)$ & Meta-analysis ${ }^{5}$ & Normal \\
\hline \multicolumn{5}{|l|}{ Relative risk of adverse event†: } \\
\hline Urinary retention & 2.89 & (1.55 to 5.42$) \ddagger$ & Meta-analysis $^{5}$ & Lognormal \\
\hline Bladder neck stenosis & 0.54 & $(0.32$ to 0.90$) \ddagger$ & Meta-analysis ${ }^{5}$ & Lognormal \\
\hline Incontinence & 2.24 & (1.03 to 4.88$) \ddagger$ & Meta-analysis ${ }^{5}$ & Lognormal \\
\hline Transfusion & 0.14 & $(0.05$ to 0.42$) \ddagger$ & Meta-analysis $^{5}$ & Lognormal \\
\hline Transurethral resection syndrome & 0.33 & (0.01 to 7.93$) \ddagger$ & Meta-analysis ${ }^{5}$ & Lognormal \\
\hline Urinary tract infection & 1.17 & $(0.60$ to 2.26$) \ddagger$ & Meta-analysis $^{5}$ & Lognormal \\
\hline Failure at 12 months & 1.68 & (1.03 to 4.88$) \ddagger$ & Meta-analysis ${ }^{5}$ & Lognormal \\
\hline Life of machine (years) & 10 & (5 to 15$) \S$ & Expert opinion & Uniform \\
\hline \multicolumn{5}{|l|}{ Microwave thermotherapy } \\
\hline Weighted mean difference in IPSS & -2.4 & $0.5(-3.4$ to $(-1.4)$ & Meta-analysis $^{4}$ & Normal \\
\hline \multicolumn{5}{|l|}{ Relative risk of adverse event†: } \\
\hline Urinary retention & 1.64 & $(0.77$ to 3.50$) \ddagger$ & Meta-analysis $^{4}$ & Lognormal \\
\hline Bladder neck stenosis & 0.2 & $(0.05$ to 0.75$) \ddagger$ & Meta-analysis ${ }^{4}$ & Lognormal \\
\hline Urinary tract infection & 1.05 & $(0.53$ to 2.08$) \ddagger$ & Meta-analysis ${ }^{4}$ & Lognormal \\
\hline Incontinence & 0.61 & $(0.30$ to 1.26$) \ddagger$ & Meta-analysis ${ }^{4}$ & Lognormal \\
\hline Transfusion & 0.11 & (0.01 to 1.98$) \ddagger$ & Meta-analysis ${ }^{4}$ & Lognormal \\
\hline Transurethral resection syndrome & 0.65 & $(0.03$ to 15.62$) \ddagger$ & Meta-analysis ${ }^{4}$ & Lognormal \\
\hline Failure at 12 months & 2.01 & (0.96 to 4.18$) \ddagger$ & Meta-analysis $^{4}$ & Lognormal \\
\hline \multicolumn{5}{|l|}{ Other risks: } \\
\hline $\begin{array}{l}\text { Failure of second treatment } \\
\text { relative to first }\end{array}$ & 0.75 & $(0.50$ to 1$) \S$ & Expert opinion & Uniform \\
\hline Reoperation at 5 years & 0.36 & 0.01 (0.33 to 0.39$)$ & Francisca et $\mathrm{al}^{21}$ & Beta \\
\hline \multicolumn{5}{|c|}{$\begin{array}{l}\text { IPSS=international prostate symptom score. } \\
\text { *Risk unless otherwise stated. } \\
\text { †Age adjusted mortality rates estimated from UK life tables and applied equally throughout time horizon without weighting according to procedure } \\
\text { †Where log distributions have been used, standard error is omitted to avoid inconsistency with confidence interval, which is expressed as actual } \\
\text { relative risk. } \\
\text { §Limits of uniform distribution. }\end{array}$} \\
\hline
\end{tabular}

international prostate symptom scores at baseline and four months after transurethral resection for a cohort of 179 men according to the criterion of less than $10 \%$ improvement in symptom score. ${ }^{18}$ For other treatments we derived this probability using individual data for transurethral resection and the weighted mean difference in the treatment effect, compared with transurethral resection, derived from a systematic review. ${ }^{45}$ Estimates of the probability of subsequent relapse were derived from meta-analyses, long term cohort studies, and consensus opinion from the clinical expert group (tables 3 and 4). The probability of failure for subsequent treatments was estimated as if there had been no previous treatment. If an individual treatment such as microwave thermotherapy or transurethral resection was used twice in a strategy then the risk of a second failure was decided by consensus of the clinical expert group.

Relapse-Relapse denoted transition from the remission to the no remission state. We calculated this for each treatment by subtracting the respective initial failure rate derived by meta-analysis from the total retreatment rate documented in studies with long term follow-up. Long term data were available only for transurethral resection and microwave thermotherapy and we therefore derived rates for other treatments from these according to the weighted mean difference in symptom score at 12 months found on meta-analysis. We calculated transition probabilities of 
subsequent relapse after initial treatment success for each three month cycle, assuming a constant rate over 10 years.

Complications - We estimated probabilities for these complications after transurethral resection by summing events across the respective treatment arms of studies carried out in the UK. Probabilities for other treatments were calculated with the relative risk reported in the meta-analysis.

Mortality-Our meta-analysis ${ }^{22}$ and a previous systematic review ${ }^{17}$ showed that there was no evidence for different mortality rates after each procedure at 12 months, while age adjusted longer term rates after transurethral resection are known to be similar to those in the general population. ${ }^{23}$ The only trial comparing transurethral resection against advice on managing symptoms alone also showed no difference in mortality rates. ${ }^{24}$ We therefore applied age specific population mortality rates for English men, irrespective of treatment or treatment sequence in line with previous economic evaluations in this area. ${ }^{7}$

\section{Costs}

We considered only hospital costs because primary care costs would be low and similar for each procedure (tables 2, 3, 4). Endoscopic procedures (diathermy or laser vaporisation, laser enucleation, and transurethral resection) were assumed to incur the same basic costs (2005 NHS reference costs for healthcare resource group (code L28), adjusted for differing length of stay by subtracting bed-day cost calculated from a nonoperative code (L09). We added appropriate extra costs for equipment, such as optical fibres for laser transmission and tissue morcellators for laser enucleation, using data provided by UK based manufacturers or distributors. As a UK reference cost for microwave thermotherapy was unavailable we calculated it using manufacturers' data from the US, day case procedure NHS reference costs, and clinical expert opinion. Capital costs of the relevant energy generator for microwave thermotherapy, laser vaporisation, and laser enucleation were derived from commercial sources. The costs of short term complications were calculated by summing costs of extra interventions, such as blood transfusion or bladder neck incision, and extra bed days calculated from the cost difference between L27 (transurethral resection with complications) and L28 (transurethral resection without complications). The cost of incontinence was derived from the drug tariff for oxybutynin multiplied by the proportion of men $(95 \%)$ having urge incontinence as defined by the clinical expert group. For the $5 \%$ of men with stress incontinence the cost was that for insertion of an artificial urinary sphincter ( $£ 6000)$.

\section{Sensitivity analysis}

\section{Probabilistic}

To test for the effect of uncertainty in parameter estimates, we used Monte Carlo simulation to select values for each parameter within the model according to a distribution around each parameter. Limits of uncertainty were defined with 95\% confidence intervals from meta-analysis, the individual dataset, NHS cost ranges, and expert opinion, with distribution shapes chosen according to standard practice (tables 2, $3,4) .{ }^{25}$ These values were then combined in the Markov model to estimate the outcome for each treatment strategy by repeating the process 10000 times and calculating the expected cost and effectiveness of each treatment sequence as the mean across all samples. We chose the number of iterations by determining the point at which addition of further samples did not result in any change in the ranking. In table 5 , in addition to the expected cost and effectiveness results, the probability that a particular strategy was cost effective was defined as the proportion of all Monte Carlo simulations using that strategy meeting the willingness to pay criterion of $£ 20000 / \mathrm{QALY} .{ }^{9}$ The figure shows results for various thresholds as a cost effectiveness acceptability curve (figure) to illustrate uncertainty regarding assignment of threshold values for willing ness to pay.

\begin{tabular}{|c|c|c|c|c|c|c|c|c|c|c|}
\hline \multirow[b]{2}{*}{ Treatment strategy } & \multirow{2}{*}{$\begin{array}{c}\text { Cost } \\
(£ 1000 s)\end{array}$} & \multirow{2}{*}{$\begin{array}{l}\text { Incremental } \\
\text { cost }(£ 1000 s)\end{array}$} & \multirow{2}{*}{$\begin{array}{l}\text { Effectiveness } \\
\text { (QALYs) }\end{array}$} & \multirow{2}{*}{$\begin{array}{l}\text { Incremental } \\
\text { effectiveness } \\
\text { (QALYs) }\end{array}$} & \multirow{2}{*}{$\begin{array}{l}\text { Incremental cost } \\
\text { effectiveness } \\
\text { ratio ( }(\text { Q QALY) }\end{array}$} & \multicolumn{5}{|c|}{$\begin{array}{l}\text { Probability of being cost effective at set willingness } \\
\text { to pay threshold }{ }^{\star}\end{array}$} \\
\hline & & & & & & $£ 5000$ & $£ 10000$ & $£ 20000$ & $£ 40000$ & $£ 80000$ \\
\hline \multicolumn{11}{|l|}{ Non-dominated strategies } \\
\hline Diathermy vaporisation & 380775 & 0 & 917082 & 0 & N/A & 0.82 & 0.03 & 0 & 0 & 0 \\
\hline $\begin{array}{l}\text { Holmium laser } \\
\text { enucleation }\end{array}$ & 400550 & 19775 & 919656 & 2574 & 7682 & 0.14 & 0.37 & 0.11 & 0.01 & 0 \\
\hline $\begin{array}{l}\text { Diathermy vaporisation + } \\
\text { holmium enucleation }\end{array}$ & 413713 & 13163 & 921041 & 1385 & 9505 & 0 & 0.57 & 0.85 & 0.80 & 0.49 \\
\hline $\begin{array}{l}\text { Diathermy vaporisation + } \\
\text { TURP repeated once if } \\
\text { necessary }\end{array}$ & 418264 & 4551 & 921091 & 50 & 90576 & 0 & 0.01 & 0.04 & 0.19 & 0.5 \\
\hline \multicolumn{11}{|l|}{ Reference strategy } \\
\hline $\begin{array}{l}\text { TURP repeated once if } \\
\text { necessary }\end{array}$ & 457866 & 39602 & 920340 & -751 & Dominated & 0 & 0 & 0 & 0.01 & 0.01 \\
\hline
\end{tabular}




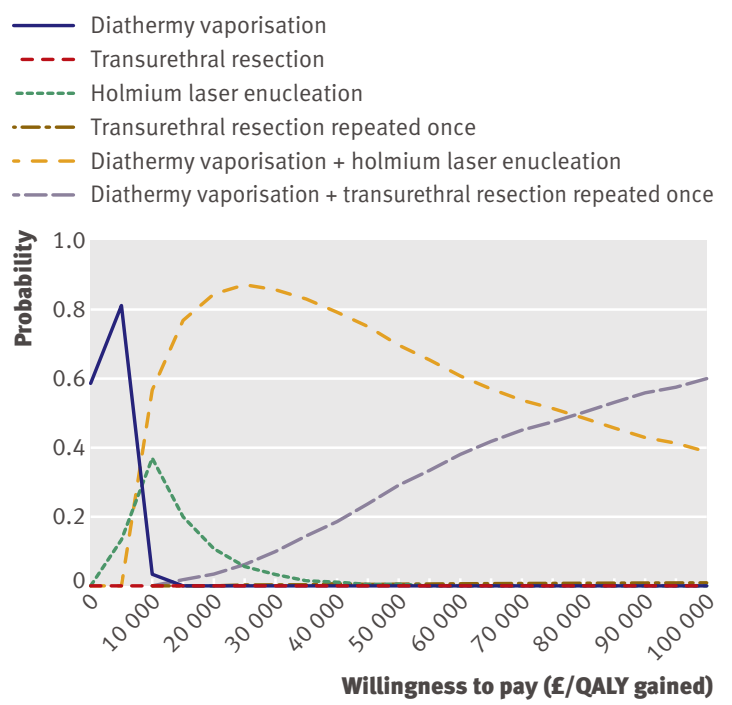

Cost effectiveness acceptability curve showing probability of being cost effective for non-dominated and reference strategies for increasing limits of willingness to pay

\section{Deterministic analysis}

We also conducted one way sensitivity analysis to test particular assumptions in the model to test the effect on outcome. These included discount rate, use of a lifetime horizon, use of a single cohort design to estimate outcome for an individual over 10 years, use of relative risk of reoperation instead of lack of symptomatic improvement to estimate relapse rates, need for urodynamic studies after relapse after diathermy or laser vaporisation, and inclusion of results from studies performed outside the UK to calculate length of stay and complication rates.

\section{RESULTS}

\section{Cost effective treatment strategies}

The strategy of initial diathermy vaporisation followed by holmium laser enucleation for men whose symptoms fail to improve or relapse after initial benefit was cost effective with a probability of 0.85 at a willingness to pay threshold of $£ 20000 /$ QLY gained (table 5, figure). In general, the use of escalating multiple treatment strategies, starting with the option of diathermy vaporisation, showed increased effectiveness and decreased cost. Both diathermy vaporisation followed by holmium laser enucleation and diathermy vaporisation followed by transurethral resection, repeated if necessary, dominated (that is, were more effective and less costly) than other strategies, including the reference standard of transurethral resection. The strategy of diathermy vaporisation followed by transurethral resection repeated if necessary became cost effective if the willingness to pay threshold was $>$ $£ 80000 /$ QALY gained. Diathermy vaporisation as a single treatment was not dominated and highly likely to be cost effective at a willingness to pay threshold of $£ 5000 /$ QALY gained. Holmium laser enucleation as a single treatment dominated transurethral resection, but the probability of it being the most cost effective strategy never exceeded 0.37. All strategies starting with microwave thermotherapy were dominated, as were those involving potassium titanyl phosphate laser vaporisation. Direct comparison between alternative strategies and the reference strategy of transurethral resection, repeated if necessary, gave similar results.

\section{Sensitivity analysis Model parameters}

Tables 6,7 , and 8 show the results of one way sensitivity analyses. If we derived the probability used to predict treatment failure from reoperation rates, as suggested by meta-analysis, then holmium laser enucleation as a single treatment became extendedly dominated by strategies starting with diathermy vaporisation. If length of stay for transurethral resection was reduced from three to two days then the current reference strategy of transurethral resection, repeated if needed, was no longer dominated by diathermy vaporisation. If performance of urodynamics was made mandatory for treatment failure after diathermy vaporisation then the standard strategy of transurethral resection, repeated if necessary, was not dominated but had an incremental cost per QALY gained of $£ 230608$. Using a single cohort of 25000 men generally showed similar incremental cost effectiveness ratios (ICER) for non-dominated strategies except for diathermy vaporisation followed by transurethral resection, repeated if necessary. Variation of all other parameters did not alter conclusions drawn from base case analysis.

\section{Effect of disaggregation}

Calculation of time spent in each health state during treatment strategies showed that most time was spent in remission (table 9). This was shortest after either microwave thermotherapy or potassium titanyl phosphate laser vaporisation and longest for sequences starting with diathermy vaporisation.

\section{DISCUSSION}

\section{Cost effective treatment}

A strategy for surgical treatment of lower urinary tract symptoms, presumed to be caused by benign prostatic enlargement, consisting of initial ablation with diathermy vaporisation followed by holmium laser enucleation for those men who experienced treatment failure or subsequent symptom relapse is cost effective given a willingness to pay threshold of $£ 20000 /$ QALY gained. This conclusion was unchanged by extensive sensitivity analysis. The model did not show any advantage for strategies involving microwave thermotherapy, consistent with results of previous studies modelling cost effectiveness of single minimally invasive treatments including microwave thermotherapy, ${ }^{72627}$ transurethral needle ablation, ${ }^{8}$ and laser coagulation. ${ }^{26-28}$ Although diathermy vaporisation as a single treatment was not dominated, it was less effective than transurethral resection and the results were sensitive to small changes in the care 
Table $6 \mid$ Results of sensitivity analysis* showing effects on cost effectiveness of variation in start age and utility value for state of incontinence

\begin{tabular}{|c|c|c|c|c|c|}
\hline Treatment strategy & Cost (£) & Incremental cost $(£)$ & $\begin{array}{l}\text { Effectiveness } \\
\text { (QALYs) }\end{array}$ & $\begin{array}{l}\text { Incremental } \\
\text { effectiveness } \\
\text { (QALYs) }\end{array}$ & $\begin{array}{l}\text { Incremental cost } \\
\text { effectiveness ratio } \\
\text { (£/QALYs) }\end{array}$ \\
\hline \multicolumn{6}{|l|}{ Base case } \\
\hline Diathermy vaporisation & 380774844 & - & 917082 & - & - \\
\hline Holmium laser enucleation & 400549783 & 19774939 & 919656 & 2574 & 7682 \\
\hline $\begin{array}{l}\text { Diathermy vaporisation + holmium laser } \\
\text { enucleation }\end{array}$ & 413712972 & 13163189 & 921041 & 1385 & 9505 \\
\hline $\begin{array}{l}\text { Diathermy vaporisation }+ \text { TURP repeated } \\
\text { once if necessary }\end{array}$ & 418264231 & 4551258 & 921091 & 50 & 90576 \\
\hline \multicolumn{6}{|l|}{ Start age 90} \\
\hline Diathermy vaporisation & 376991192 & & 541771 & & \\
\hline Holmium laser enucleation & 397495122 & 20503931 & 543268 & 1497 & 13695 \\
\hline $\begin{array}{l}\text { Diathermy vaporisation + holmium laser } \\
\text { enucleation }\end{array}$ & 405702102 & 8206980 & 543703 & 435 & 18872 \\
\hline Diathermy vaporisation + TURP & 409475528 & 3773426 & 543715 & 12 & 309087 \\
\hline \multicolumn{6}{|l|}{ Start age 50} \\
\hline Diathermy vaporisation & 381248895 & - & 1002040 & - & - \\
\hline Holmium laser enucleation & 400940948 & 19692053 & 1004857 & 2818 & 6988 \\
\hline $\begin{array}{l}\text { Diathermy vaporisation + holmium laser } \\
\text { enucleation }\end{array}$ & 414850642 & 13909693 & 1006451 & 1594 & 8727 \\
\hline $\begin{array}{l}\text { Diathermy vaporisation + TURP repeated } \\
\text { once if necessary }\end{array}$ & 419518524 & 4667882 & 1006511 & 59 & 78771 \\
\hline \multicolumn{6}{|c|}{ Utility of "incontinence-no remission" = utility of "incontinence-remission" } \\
\hline Diathermy vaporisation & 380774844 & & 917131 & - & 一 \\
\hline Holmium laser enucleation & 400549783 & 19774939 & 919679 & 2548 & 7762 \\
\hline $\begin{array}{l}\text { Diathermy vaporisation + holmium } \\
\text { vaporisation }\end{array}$ & 413712972 & 13163189 & 921092 & 1413 & 9315 \\
\hline $\begin{array}{l}\text { Diathermy vaporisation + TURP repeated } \\
\text { once if necessary }\end{array}$ & 418264231 & 4551258 & 921144 & 52 & 88045 \\
\hline
\end{tabular}

QALY=quality adjusted life year; TURP=transurethral resection of prostate.

*Based on 10000 Monte Carlo simulation samples and showing only non-dominated and non-extendedly dominated strategies.

pathway, making it unlikely to be advantageous in practice. Single treatment with holmium laser enucleation was cost effective only at a threshold of between $£ 7600$ and $£ 9500$ and its probability of being cost effective was never greater than 0.37 . In addition, it is a technically demanding procedure requiring prolonged training and a high level of competency to avoid serious adverse effects such as urinary sphincter damage and bladder perforation. It is therefore probably unsuited to widespread application and best used as the final part of a treatment sequence, administered in a few specialist centres for men who relapse after transurethral resection or vaporisation. It also became dominated by diathermy vaporisation led strategies when we recalculated reoperation rates.

The finding that potassium titanyl phosphate laser vaporisation was unlikely to be cost effective, either as a single treatment or within a treatment sequence, is important as the procedure has gained wide popularity around the world because of its perceived ease of use and reduced risk of bleeding and despite the lack of evidence of equivalent or improved effectiveness over transurethral resection. Although we obtained outcome parameters for this option from the single eligible published trial involving potassium titanyl phosphate laser vaporisation available at the time of our meta-analysis and from other trials involving vaporisation using alternative lasers, the finding was unchanged by sensitivity analysis around uncertainty in treatment benefit. In addition, a subsequent publication has noted reduced efficacy and increased retreatment rates compared with transurethral resection. ${ }^{29}$ This option was also associated with relatively high cost because of the need for one or more disposable optical fibres, but again the conclusions were not altered by sensitivity analysis around this variable and were not compensated by reduced length of stay or savings from the reduced complication rate. This result, based on current evidence, therefore does not support its current unrestricted use in clinical practice.

\section{Use of strategies}

Sequences of escalating treatments were more effective than single treatments, and this supports the need to compare clinically plausible strategies as well as oneoff treatments in clinical trials. This policy of care would be particularly attractive for large centrally managed healthcare systems, such as the UK NHS, whereby widespread use of a less morbid, technically less demanding, and cheaper option, such as diathermy vaporisation, could be widely offered as the initial treatment in various settings, whereas holmium 
Table 7|Results of sensitivity analysis* showing effects on cost effectiveness of variation in utility value of remission, risk of adverse events, length of stay, and calculation of risk of need for repeat surgery

\begin{tabular}{|c|c|c|c|c|c|}
\hline Treatment strategy & Cost $(£)$ & Incremental cost $(£)$ & $\begin{array}{l}\text { Effectiveness } \\
\text { (QALYs) }\end{array}$ & $\begin{array}{c}\text { Incremental } \\
\text { effectiveness } \\
\text { (QALYs) }\end{array}$ & $\begin{array}{l}\text { Incremental cost } \\
\text { effectiveness ratio } \\
(£ / \text { QLLs })\end{array}$ \\
\hline \multicolumn{6}{|l|}{ Utility of IPSS $<8$ is 0.97} \\
\hline Diathermy vaporisation & 380774844 & & 893516 & & \\
\hline Holmium laser enucleation & 400549783 & 19774939 & 894844 & 1328 & 14889 \\
\hline $\begin{array}{l}\text { Diathermy vaporisation + holmium } \\
\text { vaporisation }\end{array}$ & 413712972 & 13163189 & 895584 & 740 & 17791 \\
\hline $\begin{array}{l}\text { Diathermy vaporisation + TURP repeated } \\
\text { once if necessary }\end{array}$ & 418264231 & 4551258 & 895611 & 28 & 163682 \\
\hline \multicolumn{6}{|c|}{ Relative risk of adverse events from all studies } \\
\hline Diathermy vaporisation & 380774844 & & 917082 & & \\
\hline Holmium laser enucleation & 400549783 & 19774939 & 919656 & 2574 & 7682 \\
\hline $\begin{array}{l}\text { Diathermy vaporisation + holmium } \\
\text { vaporisation }\end{array}$ & 413712972 & 13163189 & 921041 & 1385 & 9505 \\
\hline \multicolumn{6}{|c|}{ Length of stay for TURP = length of stay for diathermy vaporisation $=2$ days } \\
\hline Diathermy vaporisation & 376715152 & & 917082 & & \\
\hline TURP & 380679392 & 3964240 & 918222 & 1140 & 3476 \\
\hline TURP repeated once if necessary & 400362758 & 19683366 & 920340 & 2117 & 9296 \\
\hline $\begin{array}{l}\text { Diathermy vaporisation + TURP repeated } \\
\text { once if necessary }\end{array}$ & 409495593 & 9132834 & 921091 & 751 & 12156 \\
\hline \multicolumn{6}{|c|}{ Alternative calculation of probability of failure } \\
\hline Diathermy vaporisation & 380793296 & & 918558 & & \\
\hline $\begin{array}{l}\text { Diathermy vaporisation + holmium } \\
\text { vaporisation }\end{array}$ & 404008222 & 23214926 & 921217 & 2659 & 8731 \\
\hline $\begin{array}{l}\text { Diathermy vaporisation + TURP repeated } \\
\text { once if necessary }\end{array}$ & 406972673 & 2964451 & 921269 & 52 & 56845 \\
\hline
\end{tabular}

laser enucleation, with its need for highly skilled operators, would be available in a limited number of specialised units to treat the relatively small number of men who fail to benefit or relapse after a vaporisation procedure. The findings of our study and associated systematic reviews ${ }^{45}$ suggest the need for longer term high quality trials to test the worth of such sequences of newer treatment. A multicentre head-to-head randomised controlled trial of this strategy against the standard of transurethral resection, repeated as needed, followed by a longer term "tracker" trial of the newer technologies should particularly assess the need, reason, and chosen technique for retreatment after failure or relapse. The design would need to be flexible to encompass new technologies as they emerge and account for changes in current technology, such as increased power and reduced fibre cost for laser vaporisation, and should be sufficiently powered to reduce uncertainty regarding cost effectiveness. To better judge cost effectiveness it would be necessary to consider in more detail how symptom scores map to utility values and how QALY gains estimated by disease specific symptom scores compare with estimates by using a generic instrument such as the EQ-5D. Calculation of utility values would be strengthened by qualitative research components to record preferences of individual men concerning the trade-off between reduced treatment morbidity and increased risk of reoperation.

\section{Uncertainties}

Although we have used the best available methods to define the likely outcomes of each treatment, limitations in the current evidence base lead to inevitable uncertainty regarding parameter values. Reassuringly, sensitivity analysis around appropriately selected variables did not radically change key outcomes of the model. Calculation of the expected value of perfect information according to standard practice ${ }^{30}$ suggested that an upper overall limit of $£ 5$.3m should be spent on further research to give worthwhile benefit, with specific studies of vaporisation techniques and holmium laser enucleation having upper limits of $£ 4.2 \mathrm{~m}$ and $£ 1.7 \mathrm{~m}$, respectively. These values are based on perfect rather than sample based evidence and therefore future trials should be carefully planned to deliver the required answer well within these financial constraints.

\section{Strengths of the model}

We have considered a wide variety of treatment sequences of relevance to healthcare consumers and providers in differing healthcare systems. The inclusion of minimally invasive treatments, for example, is most relevant to clinical practice in the US and Scandinavia, while holmium enucleation is mostly used in Europe and Australasia. We have also accounted for continued changes in clinical practice by including well researched but currently unpopular options such 
as diathermy vaporisation as well as recently introduced but less well evaluated procedures such as potassium titanyl phosphate laser vaporisation. Our model was based on a rigorous systematic review of the international literature. We also made strenuous efforts to be transparent in our reporting, which should allow researchers and decision makers to make judgments about the applicability of the work to their own settings. The use of a multiple cohort model allowed consideration of the diseconomies associated with using a costly, capital intensive second or third line treatment by simulating the purchasing of new equipment as required over the time horizon and avoided bias inherent in the allocation of capital costs across the whole population and time period using a single cohort technique. As a result, we believe that this model gives improved meaning regarding the effects of changing treatment policy for decision makers as well as clinicians.

\section{Limitations of the model}

Initially, we included in the model other procedures identified in the systematic review-such as bipolar diathermy resection and holmium laser vaporisation - but the number of possible treatment sequences became unmanageable and we therefore focused on technologies in current wide use or those with an extensive evidence base. Selection between vaporisation techniques with different energy sources presented a difficulty, with diathermy having the greatest evidence base but potassium titanyl phosphate laser currently being the most popular. Both were run in the model and the result in terms of cost effectiveness was markedly in favour of diathermy, despite its current unpopularity. Given that these techniques achieve the same surgical result in terms of tissue ablation it is likely that a future laser procedure, which replicates the treatment benefit and low cost of diathermy, could take its place within the sequence of cost effective treatment.

The probability of failure for treatments under study was a key parameter but difficult to quantify with certainty; lack of change in symptoms was the preferred definition but it was uncertain how this was reflected in reoperation rates published in the literature, which differed between studies. Our resolution was to use individual level data, and this seemed valid because a sensitivity analysis with a different approach gave largely consistent results. The use of a threshold of $<10 \%$ improvement in symptoms reflected the definite need for further surgery as distinct from other definitions of treatment success used in trials of treatment. It would, however, be important to validate this threshold in future studies by prospectively recording reasons for retreatment. Mapping of symptom scores to utility values was another difficulty, which we resolved by synthesising available data. Again sensitivity analysis suggests that our approach was reasonable, although the need for further research in this area is acknowledged.

Costs were deliberately based on the setting of the NHS in England because this provided the most comprehensive source of data, and, again, sensitivity analysis suggests that the choices made were robust, although translation to other healthcare systems might not be clear cut. We did not consider costs associated with staff retraining and service reconfiguration required to change practice away from the standard of transurethral resection, but these are likely to be small if the cost effective strategy of vaporisation followed by holmium resection in the case of failure or relapse is adopted as sufficient capacity already exists. Any healthcare provider, however, would need to consider the opportunity cost of switching funding from another area to implement the policy change.

Table $8 \mid$ Results of sensitivity analysis* showing effects on cost effectiveness of variation in use of urodynamic test after failed surgery and use of single cohort model

\begin{tabular}{|c|c|c|c|c|c|}
\hline Treatment strategy & Cost $(£)$ & Incremental cost $(£)$ & $\begin{array}{l}\text { Effectiveness } \\
\text { (QALYs) }\end{array}$ & $\begin{array}{c}\text { Incremental } \\
\text { effectiveness } \\
\text { QALYs) }\end{array}$ & $\begin{array}{l}\text { Incremental cost } \\
\text { effectiveness ratio } \\
(£ / Q A L Y s)\end{array}$ \\
\hline \multicolumn{6}{|c|}{ Urodynamic test mandatory after failed diathermy vaporisation } \\
\hline Diathermy vaporisation & 380774844 & - & 917082 & - & - \\
\hline Holmium laser enucleation & 400549783 & 19774939 & 919656 & 2574 & 7682 \\
\hline $\begin{array}{l}\text { Diathermy vaporisation + holmium } \\
\text { vaporisation }\end{array}$ & 405478440 & 4928657 & 920051 & 395 & 12475 \\
\hline $\begin{array}{l}\text { Diathermy vaporisation + TURP repeated } \\
\text { once if necessary }\end{array}$ & 409175523 & 3697083 & 920128 & 78 & 47659 \\
\hline TURP repeated once if necessary & 457866096 & 48690573 & 920340 & 211 & 230608 \\
\hline \multicolumn{6}{|l|}{ Single cohort model } \\
\hline Diathermy vaporisation & 1794 & & 7.12 & & \\
\hline Holmium laser enucleation & 1819 & 25 & 7.14 & 0.0202 & 1242 \\
\hline $\begin{array}{l}\text { Diathermy vaporisation + holmium } \\
\text { vaporisation }\end{array}$ & 1958 & 139 & 7.15 & 0.0129 & 10755 \\
\hline $\begin{array}{l}\text { Diathermy vaporisation + TURP repeated } \\
\text { once if necessary }\end{array}$ & 1990 & 31 & 7.15 & 0.0005 & 60896 \\
\hline
\end{tabular}


Table $9 \mid$ Time spent in each state of Markov model for base case disaggregated from quality of life and ranked in descending order according to time in remission state

\begin{tabular}{|c|c|c|c|c|c|}
\hline \multirow[b]{2}{*}{ Treatment strategy } & \multicolumn{5}{|c|}{ Time in health state* (years) } \\
\hline & Treatment & Remission & No remission & Incontinence $†$ & Death \\
\hline $\begin{array}{l}\text { Diathermy vaporisation + TURP repeated once } \\
\text { if necessary } \neq\end{array}$ & 0.27 & 7.92 & 0.04 & 0.09 & 1.67 \\
\hline $\begin{array}{l}\text { Diathermy vaporisation + holmium laser } \\
\text { enucleation } \ddagger\end{array}$ & 0.27 & 7.91 & 0.05 & 0.09 & 1.67 \\
\hline Diathermy vaporisation + TURP & 0.27 & 7.89 & 0.07 & 0.09 & 1.67 \\
\hline TURP repeated once if necessary§ & 0.26 & 7.78 & 0.18 & 0.10 & 1.67 \\
\hline $\begin{array}{l}\text { Microwave thermotherapy + diathermy } \\
\text { vaporisation + TURP }\end{array}$ & 0.36 & 7.75 & 0.13 & 0.09 & 1.67 \\
\hline $\begin{array}{l}\text { Microwave thermotherapy + diathermy } \\
\text { vaporisation + TURP repeated once if } \\
\text { necessary }\end{array}$ & 0.36 & 7.75 & 0.12 & 0.09 & 1.67 \\
\hline $\begin{array}{l}\text { Microwave thermotherapy + diathermy } \\
\text { vaporisation + holmium laser enucleation }\end{array}$ & 0.36 & 7.75 & 0.12 & 0.09 & 1.67 \\
\hline $\begin{array}{l}\text { Microwave thermotherapy + TURP repeated } \\
\text { once if necessary }\end{array}$ & 0.36 & 7.71 & 0.16 & 0.09 & 1.67 \\
\hline $\begin{array}{l}\text { Microwave thermotherapy repeated once+ } \\
\text { diathermy vaporisation + TURP }\end{array}$ & 0.40 & 7.68 & 0.16 & 0.09 & 1.67 \\
\hline $\begin{array}{l}\text { Microwave thermotherapy repeated once + } \\
\text { diathermy vaporisation + TURP repeated once } \\
\text { if necessary }\end{array}$ & 0.40 & 7.68 & 0.16 & 0.09 & 1.67 \\
\hline $\begin{array}{l}\text { Microwave thermotherapy + holmium laser } \\
\text { enucleation }\end{array}$ & 0.35 & 7.68 & 0.21 & 0.09 & 1.67 \\
\hline $\begin{array}{l}\text { Microwave thermotherapy repeated once + } \\
\text { diathermy vaporisation + holmium laser } \\
\text { enucleation }\end{array}$ & 0.40 & 7.68 & 0.16 & 0.09 & 1.67 \\
\hline $\begin{array}{l}\text { Microwave thermotherapy repeated once + } \\
\text { TURP repeated once if necessary }\end{array}$ & 0.40 & 7.67 & 0.17 & 0.09 & 1.67 \\
\hline $\begin{array}{l}\text { Microwave thermotherapy repeated once }+ \\
\text { holmium laser enucleation }\end{array}$ & 0.40 & 7.66 & 0.19 & 0.09 & 1.67 \\
\hline Holmium laser enucleation $\ddagger$ & 0.25 & 7.65 & 0.33 & 0.09 & 1.67 \\
\hline $\begin{array}{l}\text { Microwave thermotherapy repeated once + } \\
\text { TURP }\end{array}$ & 0.40 & 7.63 & 0.21 & 0.09 & 1.67 \\
\hline $\begin{array}{l}\text { Microwave thermotherapy repeated once + } \\
\text { diathermy vaporisation }\end{array}$ & 0.40 & 7.62 & 0.23 & 0.08 & 1.67 \\
\hline Microwave thermotherapy + TURP & 0.35 & 7.61 & 0.27 & 0.09 & 1.67 \\
\hline $\begin{array}{l}\text { Microwave thermotherapy + diathermy } \\
\text { vaporisation }\end{array}$ & 0.35 & 7.56 & 0.33 & 0.08 & 1.67 \\
\hline TURP§ & 0.25 & 7.44 & 0.55 & 0.09 & 1.67 \\
\hline Diathermy vaporisation $†$ & 0.25 & 7.27 & 0.72 & 0.09 & 1.67 \\
\hline Microwave thermotherapy repeated once & 0.35 & 6.82 & 1.08 & 0.08 & 1.67 \\
\hline Potassium titanyl phosphate vaporisation & 0.25 & 5.65 & 2.21 & 0.21 & 1.67 \\
\hline Microwave thermotherapy & 0.25 & 5.28 & 2.74 & 0.06 & 1.67 \\
\hline \multicolumn{6}{|c|}{$\begin{array}{l}\text { TURP=transurethral resection of prostate. } \\
\text { *Not discounted. } \\
\text { †Includes “incontinence-no remission" and "incontinence-remission." } \\
\text { †Non-dominated strategy. } \\
\text { §Reference strategy. }\end{array}$} \\
\hline
\end{tabular}

The population studied in the model was sufficiently healthy to undergo any of the procedures. In practice, men with comorbidities resulting in an excessive risk of bleeding or fluid imbalance tend to be advised against transurethral resection. For these men, less morbid procedures, such as microwave therapy and potassium titanyl phosphate laser vaporisation, offer the opportunity for treatment and indeed are in widespread use for this indication, but inclusion of this scenario would have greatly increased the complexity of our model. Our remit was focused on surgical treatment and we therefore assumed that men entering the model had already tried and failed conservative management in the form of advice on fluid management or drug treatment. In future research it would be useful to add these options at the start of treatment strategies to determine overall cost effectiveness of all options available for the management of this condition.

\section{Conclusion}

Current evidence suggests a sequence of treatments consisting of initial diathermy vaporisation followed by either holmium laser enucleation or transurethral resection, repeated if necessary on failure or relapse, 


\section{WHAT IS ALREADY KNOWN ON THIS TOPIC}

Benign enlargement of the prostate is a common chronic health condition for ageing men, with 25000 undergoing surgical treatment in England each year at a cost of $£ 53 \mathrm{~m}$

Newer surgical techniques such as laser or diathermy vaporisation show similar efficacy to the standard treatment of transurethral resection with reduced morbidity

The trade-off for this benefit is higher retreatment rates, which might incur higher costs

\section{WHAT THIS STUDY ADDS}

A treatment strategy of initial diathermy vaporisation followed by laser enucleation for those who fail to benefit or subsequently relapse seems cost effective

The currently popular option of potassium titanyl phosphate laser ablation was unlikely to be cost effective in this model

In the absence of strong evidence in favour of newer methods, transurethral resection, repeated if necessary, remains clinically effective and is well established

are cost effective strategies for surgical treatment of symptoms presumed to be caused by benign enlargement of the prostate. Given uncertainty about the willingness to pay threshold for a gain in QALYs, single treatment with either diathermy vaporisation or holmium laser enucleation could also be cost effective. Limitations in available data might affect the results of the cost effectiveness analysis and additional opportunity costs might negate savings made by changing from the current highly clinically effective established standard of transurethral resection.

Other members of the BPE team are Angela Coutts, Cynthia Fraser, Adrian Grant, Tania Lourenco, Graeme MacLennan, Graham Mowatt, and Susan Wong. We thank our clinical colleagues and the device manufacturers who freely gave their advice and information on costs. Freely available NHS data were obtained from www.hesonline.nhs.uk courtesy of the NHS Information Centre and from www.dh.gov.uk/PolicyAndGuidance/ OrganisationPolicy/FinanceAndPlanning/NHSReferenceCosts courtesy of the Department of Health

Contributors: NA coordinated the study, constructed the Markov model, carried out data analyses, cowrote the manuscript, and is guarantor. LV provided expert methodological and analytical advice and commented on drafts of the manuscript. MD provided methodological advice. GN and SM were members of the clinical expert group and commented on drafts of the manuscript. JN'D led and coordinated the BPE project, was a member of the clinical expert group, and commented on the manuscript. RP assisted in conceiving and constructing the model, coordinated the analysis, cowrote the manuscript, was a member of the clinical expert group, and is guarantor. All authors declare that they accept full responsibility for the conduct of the study, had access to the data, and controlled the decision to publish.

Funding: This study was funded by the Health Technology Assessment Programme (project No 04/38/03). The views expressed in this paper are those of the authors not the institutions providing funding. An extensive monograph describing the whole project of which this analysis is a part is available for open access (Lourenco T, Armstrong N, N'Dow J, Nabi G, Deverill M, Pickard R, et al. Systematic review and economic modelling of effectiveness and cost utility of surgical treatments for men with benign prostatic enlargement. Health Technol Assess 2008;12:1516).

Competing interests: None declared

Ethical approval: Not required.

1 Boyle P, Robertson C, Mazzetta C, Keech M, Hobbs FD, Fourcade R, et al. The prevalence of lower urinary tract symptoms in men and women in four centres. The UrEpik study. BJU Int 2003;92:409-14.

2 Emberton M, Andriole GL, De La Rosette J, Djavan B, Hoefner K, Vela NR, et al. Benign prostatic hyperplasia: a progressive disease of aging men. Urology 2003;61:267-73.

3 Mebust WK, Holtgrewe HL, Cockett AT, Peters PC. Transurethral prostatectomy: immediate and postoperative complications. A cooperative study of 13 participating institutions evaluating 3,885 patients. J Urol 1989;141:243-7.

4 Lourenco T, Pickard R, Vale L, Grant A, Fraser C, MacLennan G, et al. Minimally invasive treatments for benign prostatic enlargement: systematic review of randomised controlled trials. BMJ 2008;337:a1662.

5 Lourenco T, Pickard R, Vale L, Grant A, Fraser C, MacLennan G et al. Alternative approaches to endoscopic ablation for benign enlargement of the prostate: systematic review of randomised controlled trials. BMJ 2008;337:a449.

6 Blute M, Ackerman SJ, Rein AL, Beusterien K, Sullivan EM, Tanio CP et al. Cost effectiveness of microwave thermotherapy in patients with benign prostatic hyperplasia: part II-results. Urology 2000;56:981-7.

7 DiSantostefano RL, Biddle AK, Lavelle JP. The long-term cost effectiveness of treatments for benign prostatic hyperplasia. Pharmacoeconomics 2006;24:171-91.

8 Howard K, Wortley S. Transurethral needle ablation (TUNA) for the treatment of benign prostatic hyperplasia. MSAC application 1014. Canberra: Medical Services Advisory Committee, 2002. www.msac.gov.au/internet/msac/publishing.nsf/Content/ 1014-1.

9 National Institute for Health and Clinical Excellence. The guidelines manual 2007. www.nice.org.uk/aboutnice/howwework/ developingniceclinicalguidelines/ clinicalguidelinedevelopmentmethods/theguidelinesmanual2007/ the_guidelines_manual_2007.jsp

10 Stafinski T, Menon D, Harris K, Maddern GG, Jhangri G. Photoselective vaporization of the prostate for the treatment of benign prostatic hyperplasia. Can Urol Assoc J 2008;2:124-34.

11 Tooher R, Sutherland P, Costello A, Gilling P, Rees G, Maddern G. A systematic review of holmium laser prostatectomy for benign prostatic hyperplasia. J Urol 2004;171:1773-81.

12 Barry MJ, Williford WO, Yuchiao C, Machi M, Jones KM, Walker-Corkery E, et al. Benign prostatic hyperplasia specific health status measures in clinical research: how much change in the American urological association symptom index and the benign prostatic hyperplasia impact index is perceptible to patients? J Urol 1995;154:1770-74.

13 Watson V, Ryan M, Brown CT, Barnett G, Ellis BW, Emberton M. Eliciting preferences for drug treatment of lower urinary tract symptoms associated with benign prostatic hyperplasia. J Urol 2004;172:2321-25.

14 Wasson JH, Reda DJ, Bruskewitz RC, Elinson J, Keller AM, Henderson WG. A comparison of transurethral surgery with watchfu waiting for moderate symptoms of benign prostatic hyperplasia. The Veterans Affairs Cooperative Study Group on Transurethral Resection of the Prostate. N Engl J Med 1995;332:75-9.

15 Kok ET, McDonnell J, Stolk EA, Stoevelaar HJ, Busschbach JJV. The valuation of the international prostate symptom score (IPSS) for use in economic evaluations. Eur Urol 2002;42:491-97.

16 Ackerman SJ, Rein AL, Blute M, Beusterien K, Sullivan EM, Tanio CP, et al. Cost effectiveness of microwave thermotherapy in patients with benign prostatic hyperplasia: part I-methods. Urology 2000;56:972-80.

17 NHS reference costs. NHS Trusts elective in-patient HRG data. London: Department of Health,

2005. www.dh.gov.uk/PolicyAndGuidance/OrganisationPolicy/ FinanceAndPlanning/NHSReferenceCosts/fs/en.

18 Harding C, Robson W, Drinnan M, Sajeel M, Ramsden P, Griffiths C, et al. Predicting the outcome of prostatectomy using non-invasive bladder pressure and urine flow measurements. Eur Urol 2007;52:186-192.

19 American Urological Association. Guideline on the management of benign prostatic hyperplasia (BPH). Linthicum, MD: American Urological Association, 2003. www.auanet.org/guidelines/bph.cfm.

20 Madersbacher S, Lackner J, Brossner C, Rohlich M, Stancik I, Willinger $\mathrm{M}$, et al. Reoperation, myocardial infarction and mortality after transurethral and open prostatectomy: a nation-wide, long-term analysis of 23,123 cases. Eur Urol 2005;47:499-504.

21 Francisca EA, d’Ancona FC, Meuleman EJ, Debruyne FM, de la Rosette JJ. Sexual function following high energy microwave thermotherapy: results of a randomized controlled study comparing transurethral microwave thermotherapy to transurethral prostatic resection. J Urol 1999;161:486-90.

22 Lourenco T, Armstrong N, N’Dow J, Nabi G, Deverill M, Pickard R, et al. Systematic review and economic modelling of effectiveness and cost utility of surgical treatments for men with benign prostatic enlargement. Health Technol Assess 2008;12:1-516.

23 Seagroatt V. Mortality after prostatectomy: selection and surgical approach. Lancet 1995;346:1521-4

24 Wasson JH, Reda DJ, Bruskewitz RC, Elinson J, Keller AM, Henderson WG. A comparison of transurethral surgery with watchful waiting for moderate symptoms of benign prostatic hyperplasia. The 
Veterans Affairs Cooperative Study Group on Transurethral Resection of the Prostate. N Engl J Med 1995;332:75-9.

25 Briggs A. Handling uncertainty in economic evaluations and presenting the results. In: McGuire DM, McGuire A, eds. Economic evaluation in health care: merging theory with practice. Oxford: Oxford University Press, 2001.

26 Norby B, Nielsen HV, Frimodt-Moller PC. Cost-effectiveness of new treatments for benign prostatic hyperplasia: results of a randomized trial comparing the short-term cost-effectiveness of transurethral interstitial laser coagulation of the prostate, transurethral microwave thermotherapy and standard transurethral resection or incision of the prostate. Scand J Urol Nephrol 2002;36:286-95.

27 Stovsky MD, Griffiths RI, Duff SB. A clinical outcomes and cost analysis comparing photoselective vaporization of the prostate to alternative minimally invasive therapies and transurethral prostate resection for the treatment of benign prostatic hyperplasia. J Urol 2006;176:1500-6.
28 Noble SM, Coast J, Brookes S, Neal DE, Abrams P, Peters TJ, Donovan JL. Transurethral prostate resection, non-contact laser therapy or conservative management in men with symptoms of benign prostatic enlargement? An economic evaluation. J Urol 2002; 168:2476-82.

29 Horasanli K, Silay MS, Altay B, Tanriverdi O, Sarica K, Miroglu C. Photoselective potassium titanyl phosphate (KTP) laser vaporization versus transurethral resection of the prostate for prostates larger than $70 \mathrm{ml}$ : a short-term prospective randomized trial. Urology 2008;71:247-51

30 Ades AE, Lu G, Claxton K. Expected value of sample information calculations in medical decision modelling. Med Decis Making 2004;24:207-27.

Accepted: 2 Jan 2009 